\title{
Polypyrrole-based Conducting and Antibacterial Hybrid Cellulose Membranes: A Study on the Effect of UV Exposure on the Conductivity and Formation of Silver Nanoparticles
}

\author{
Zahid Hanif, ${ }^{1,2 \dagger}$ Zeeshan Ahmad Khan, ${ }^{1 \dagger}$ Mohd Farhan Siddiqui, ${ }^{1}$ \\ Seungkyung Park, ${ }^{1 *}$ and Sung Jea Park ${ }^{1,2^{* *}}$ \\ ${ }^{1}$ School of Mechanical Engineering, Korea University of Technology and Education (KOREATECH), \\ Cheonan 31253, Republic of Korea \\ ${ }^{2}$ Advanced Technology Research Center, Korea University of Technology and Education (KOREATECH), \\ Cheonan 31253, Republic of Korea
}

(Received January 23, 2019; accepted April 22, 2019)

Keywords: polypyrrole, cellulose membrane, conductive hybrid, photothermal reduction, silver nanoparticles, antibacterial activity

The development of hybrid materials with multiple uses by an eco-friendly method is becoming paramount in the field of materials science. The vapor-phase polymerization being an easy, cheap and environmentally friendly method is used to prepare cellulosepolypyrrole (Cell-PPy) hybrid membranes. These hybrid membranes are further deposited with silver nanoparticles through a UV-assisted photoreduction process (Cell-PPy-Ag). The hybrid membranes have been characterized by X-ray powder diffraction (XRD), scanning electron microscopy (SEM), and thermogravimetric analysis (TGA), which reveals a consistent homogenous polymerization of pyrrole on the surface of the cellulose paper filter. The conductivity behaviors of the Cell-PPy (doped and undoped) and Cell-PPy-Ag hybrid membranes have also been investigated, and the obtained results reflect good conducting properties that can be utilized for the development of flexible electrochemical sensors and other biomedical applications. Furthermore, we investigated the antibacterial nature of the Cell-PPyAg hybrid membranes with both gram-negative and gram-positive bacteria, Escherichia coli and Staphylococcus aureus, respectively. In this research, we present a simple, eco-friendly, and cost-effective means of mass-producing dual-functional Cell-PPy-Ag membranes with conductivity and antibacterial property.

\section{Introduction}

There has been mounting interest in designing novel hybrid materials with multiple applications. Conducting polymers and their hybrids have drawn considerable attention owing to their outstanding electrical and optical properties. ${ }^{(1)}$ Additionally, flexibility, scaleup synthesis, and lightweight enable the utilization of conducting polymers and their hybrids

\footnotetext{
*Corresponding author: e-mail: spark@koreatech.ac.kr

${ }^{* *}$ Corresponding author: e-mail: psj7517@koreatech.ac.kr

${ }^{\dagger}$ These authors contributed equally to this work.

https://doi.org/10.18494/SAM.2019.2310
} 
for versatile applications in different fields such as environmental monitoring, energy, and filtration. ${ }^{(2-4)}$ Polypyrrole (PPy) is one of the most studied conjugated conducting polymers among a large class of conducting polymers owing to its biocompatibility, nontoxicity, stability, and cost-effective processing. ${ }^{(5)}$ These features make it applicable to numerous fields such as drug delivery, electronic devices, chemical sensors, catalyst support in a fuel cell, waterresistant sponges, and even in making artificial muscles. ${ }^{(6-8)}$ However, the lack of antimicrobial property limits its applications in biomedical devices, membrane filters, and food packaging. PPy hybrids usually suffer from poor processing, which forms poorly conducting powder owing to the formation of a nonuniform conjugated structure. Moreover, the complicated nature of synthesis is not suitable for mass production. ${ }^{(9)}$ A few methods are eco-friendly, but their mediocre conductivity is a major limitation. ${ }^{(10)}$ Formulating a simple, eco-friendly method of developing a PPy hybrid with antimicrobial property will be helpful in enhancing the applicability of these well-studied polymers and their hybrids.

The surface polymerization of pyrrole monomers has successfully transformed the nonconducting insulating hydrophobic substrates (polyester, silk, wool, and aramid) to conducting flexible substrates that open up avenues for subsequent smart applications. ${ }^{(11-13)}$ Paper is a form of cellulose regularly used in writing, printing, cleaning, decorating, and packing. Additionally, paper as a filter is readily used as a support for polymers to develop novel functional materials. ${ }^{(14)}$ The wide availability, nontoxicity, structural diversity (fiber, gel, sheet, and membrane), biodegradability, and easy recyclability make cellulose a promising material for numerous applications. ${ }^{(15)}$ Moreover, cellulosic filter paper modified with silver nanoparticles is utilized for the development of sensors and filtration membranes. ${ }^{(16,17)}$

PPy has also been used for the uniform coating of individual cellulose fibers through the oxidative polymerization of pyrrole monomers on different substrates at low temperatures. ${ }^{(18)}$ However, the bulk polymerization of PPy in one reaction chamber is a major drawback that makes oxidative polymerization environmentally unfriendly. ${ }^{(19)}$ The electrodeposition of PPy, on the other hand, is only suitable for conductive substrates such as indium tin oxide (ITO), stainless steel, and platinum. ${ }^{(20-22)}$ A comparatively simple, facile, and green process, namely, vapor phase polymerization, has emerged as an alternative approach to coating PPy on various substrates (conducting and nonconducting) with different morphologies under ambient conditions. ${ }^{(23)}$ Following the vapor phase polymerization, PPy has been uniformly coated on a flexible PDMS substrate to form a strain sensor that shows high strain, sensitivity, and good stability. ${ }^{(24)}$

Owing to their antibacterial property, high electrical conductivity, and nontoxicity, silver nanoparticles (AgNPs) are utilized to design novel functional nanocomposites. ${ }^{(25)}$ The formation of metal nanoparticles ( $\mathrm{Ag}, \mathrm{Au}$, and $\mathrm{Pd}$ ) on a solid matrix such as cellulose by different methods (in situ reduction and electrostatic assembly) is widely accepted. ${ }^{(26)}$ The development of flexible conducting fabrics and wool biomacromolecule fibers coated with silver nanoparticles is of additional interest. Furthermore, researchers have also shown the formation of $\mathrm{Ag}, \mathrm{Au}$, and $\mathrm{Cu}$ nanoparticles on substrates covered with a PPy film. ${ }^{(27)}$ Aforementioned nanocomposites are striking with respect to their sensitivity, conductivity, and stability; the process involved in their synthesis, however, utilizes toxic harmful and expensive reagents, such as acetonitrile and sodium borohydride $\left(\mathrm{NaBH}_{4}\right)$, and expensive ionic liquids. 
In this study, we demonstrated an efficient, green, and nontoxic process to form cellulosepolypyrrole (Cell-PPy) hybrid membranes through vapor phase polymerization with iron chloride as an oxidant and further functionalization with silver nanoparticles through UVassisted photoreduction, thereby avoiding toxic and expensive reducing agents. The prepared hybrid membranes were characterized by X-ray powder diffraction (XRD), scanning electron microscopy (SEM), and thermogravimetric analysis (TGA). The formation of Cell-PPy-Ag hybrid membranes, owing to the presence of conducting PPy and the antibacterial effect of silver nanoparticles, prompted us to investigate their conducting and antimicrobial behaviors. The moderate conductivity and antibacterial behavior against nonresistant strains of Escherichia coli and Staphylococcus aureus were observed in all prepared Cell-PPy-Ag hybrids.

\section{Materials and Methods}

\subsection{Materials}

Cellulose filter papers (55 mm diameter) were purchased from Hyundai Micro (South Korea). Pyrrole (98\%) was purchased from Alfa Aesar (USA), ferric chloride ( $\mathrm{FeCl}_{3}$, anhydrous) was purchased from Sigma Aldrich, ammonia solution was purchased from Junsei Chemicals Co. (Japan), and silver nitrate was purchased from Tokyo Chemical Industry (Japan). All chemicals were used without any further purification.

\subsection{Preparation of Cell-PPy hybrid}

Conductive hybrids were prepared by the vapor-phase polymerization of pyrrole monomers as depicted in Fig. 1(a). We proposed a simple impregnation technique to polymerize a conjugated polymer (PPy) on a cellulose membrane. ${ }^{(28)}$ First, the membrane was impregnated by dipping it in an aqueous solution of metal salt $\left(\mathrm{FeCl}_{3}\right.$, as an oxidant), which was prepared by

(a)
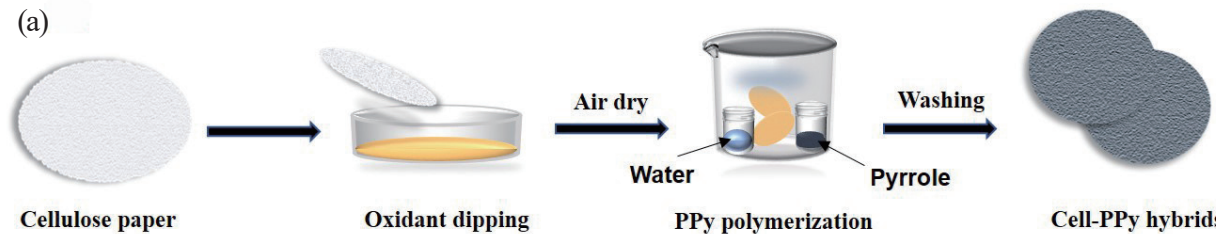

PPy polymerization

Cell-PPy hybrids

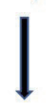

(b)
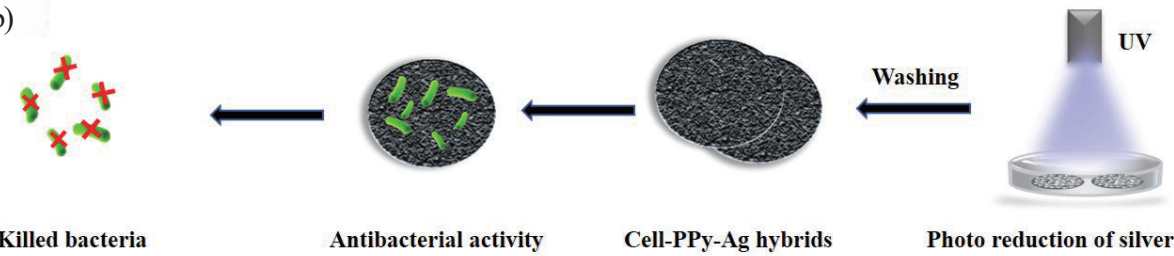

Killed bacteria

Antibacterial activity

Cell-PPy-Ag hybrids

Photo reduction of silver salt

Fig. 1. (Color online) Schematic representation of fabrication of (a) Cell-PPy and (b) Cell-PPy-Ag hybrid membranes. 
dissolving the metal salt in water, with different molar concentrations of oxidant $(0.25,0.5$, and $1 \mathrm{M})$ for $1 \mathrm{~h}$ and then exposed to open air to dry under ambient conditions. Subsequently, all metal-salt containing cellulose membranes (deep yellow color) were exposed to pyrrole vapor. In this process, the oxidant-impregnated dried cellulose membranes were placed in an air-tight vessel (1 liter) that contained $20 \mathrm{ml}$ of water and $2 \mathrm{ml}$ of pyrrole monomers in two separate glass vials for vapor-phase polymerization (Fig. 1). Different periods (15, 30, 60, and $120 \mathrm{~min}$ ) were employed for the vapor-phase polymerization of pyrrole on iron (III)-containing cellulose membranes. The progress of polymerization was noted by the change in the color of the membranes from yellowish orange to dark brown and finally to black. Thereafter, we removed the pyrrole-polymerized (black-colored) membranes from the closed vessel and thoroughly washed them several times with deionized water and then with methanol, so that any unreacted metal salt, pyrrole monomer, or oligomers could be removed. Finally, these polypyrrole-coated cellulose (Cell-PPy) hybrids were exposed to air at room temperature until they were fully dried to investigate their conductivity. After that, all the samples were fully doped by immersing in $1 \%$ hydrochloric acid for 30 min to incorporate a counter ion $(\mathrm{Cl})$ into a PPy ring to make it fully conducting by decreasing the internal bond angle of the PPy ring and undoped in 1\% liquid ammonia for $1 \mathrm{~h}$ to remove the counter ion $\left(\mathrm{Cl}^{-}\right)$from the PPy ring to minimize the conductivity by increasing the bond angle of the PPy ring in the hybrid membranes, followed by washing with plenty of deionized water in each case and full air drying. Finally, the electrical conductivities of the doped and undoped hybrids were measured.

\subsection{Deposition of silver particles on the Cell-PPy hybrid}

The subsequent deposition of silver nanoparticles on the Cell-PPy hybrids is shown in Fig. 1(b). A handheld UV source of $345 \mathrm{~nm}$ wavelength was used for this study. Two different aqueous molar concentrations $(5 \mathrm{mM}$ and $0.5 \mathrm{M})$ of silver nitrate were prepared. Cell-PPy hybrids (doped and undoped) were immersed in an aqueous silver nitrate solution for different periods in the presence of $(20,40$, and $60 \mathrm{~min})$ and absence of $\mathrm{UV}(1,15$, and $24 \mathrm{~h})$ irradiation. After that, the Cell-PPy hybrid membranes were removed from the aqueous silver salt solution and thoroughly washed with deionized water to remove any loosely bound silver ions. Finally, the treated membranes were air-dried under ambient conditions to study their conductivity and antibacterial activity.

\subsection{Characterization}

SEM images were obtained using a scanning electron microscopy system (JSM-7500, JEOL Ltd, Japan) to study the surface morphology of the Cell-PPy hybrid membranes and the silver nanoparticle distribution on the surface of the nanohybrid membranes. The conductivity of the hybrid membranes was measured by a standard four-probe technique. A thermogravimetric analysis system (TGA, Q500, TA Instrument, USA) was utilized to observe the thermal stability and calculate the number of silver particles present in the Cell-PPy hybrid membranes. The thickness of the Cell-PPy hybrid membranes after the pyrrole polymerization and silver nanoparticle deposition was measured using a digital display screw gauge micrometer. Rigaku $\mathrm{XRD}, \mathrm{Cu}$ radiation, $\lambda=0.1546 \mathrm{~nm}$, at $40 \mathrm{kV}$ and $30 \mathrm{~mA}$ was used for $\mathrm{X}$-ray diffraction studies. 


\subsection{Antibacterial activity}

The antibacterial activity was assessed by the disk diffusion method (Kirby-Bauer test). The bacterial samples of E. coli and S. aureus obtained from the Korean Collection for Type Culture (KCTC) and the Korean Culture Center of Microorganisms (KCCM), respectively, were prepared from single overnight-grown colonies suspended in a test tube containing LB broth (BD Difco, UK) and incubated at $37{ }^{\circ} \mathrm{C}$ with shaking. The turbidity of the cultured bacterial suspensions was measured using an optical spectrophotometer (SpectraMax, Molecular Devices, USA) [optical density (OD) at $\lambda=600 \mathrm{~nm}$ ] until the $0.50 \mathrm{McFarland}$ unit. $100 \mu \mathrm{l}$ of the grown culture was plated on MH agar (BD Difco, UK) plates. Cellulose, Cell-PPy, and CellPPy-Ag membranes of $5 \mathrm{~mm}$ were cut out and placed on top of the plated bacterial cultures, and the samples were incubated at $37{ }^{\circ} \mathrm{C}$. Thereafter, the inhibition zones around the discs were measured. ${ }^{(29)}$

\section{Results and Discussion}

The green synthesis of the dual-functional surface having conducting and antibacterial properties was carried out in two major steps. Primarily, the cellulose membrane surface was coated with PPy followed by the decoration of silver nanoparticles. The cellulose was classified into four crystallization structures, namely, I, II, III, and IV, and all four showed distinct peaks when subjected to XRD. The XRD spectra of the pristine cellulose (membrane filter) clearly indicated the characteristic peaks of cellulose II at 12.1, 19.8, and $22^{\circ}$ [Fig. 2(a-i)]. The Cell-PPy

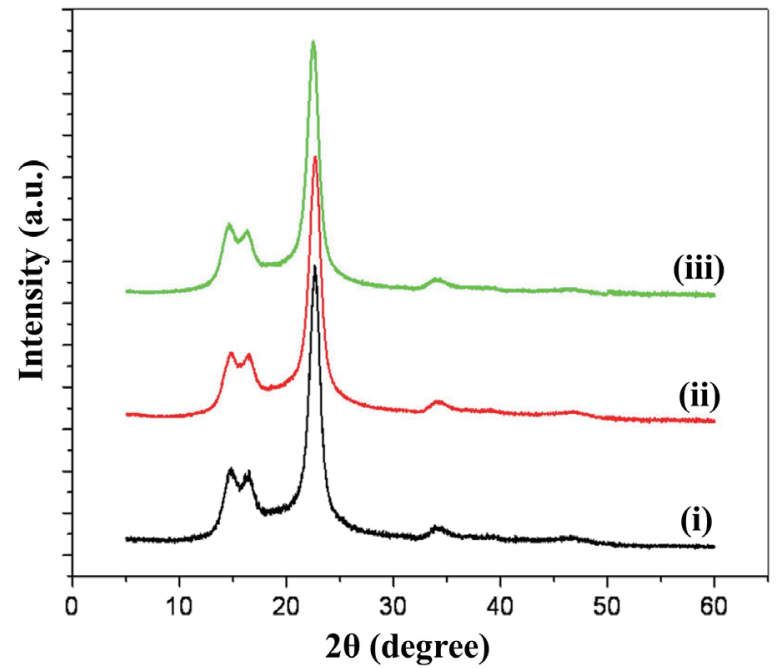

(a)

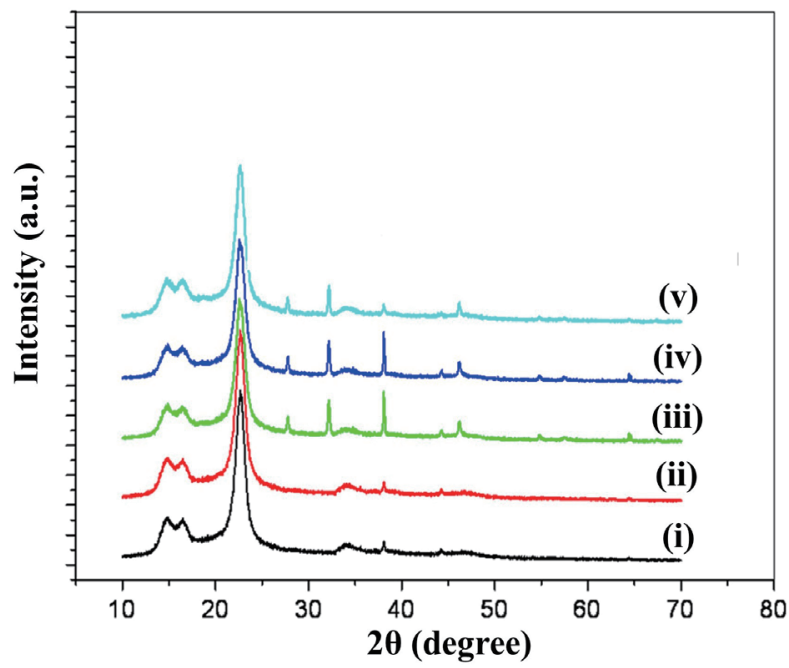

(b)

Fig. 2. (Color online) XRD spectra of (a-i) cellulose (Cell), (a-ii) cellulose-polypyrrole [(Cell-PPy) doped state] and (a-iii) Cell-PPy (undoped state), (b) Cell-PPy-Ag (b-i) $0.5 \mathrm{M} \mathrm{AgNO}_{3}$ and (b-ii) $5 \mathrm{mM} \mathrm{AgNO}_{3}$ (undoped state in the absence of UV) (b-iii) $0.5 \mathrm{M} \mathrm{AgNO}_{3}$, (b-iv) $5 \mathrm{mM} \mathrm{AgNO}_{3}$ (doped state in the presence of UV), and (b-v) $5 \mathrm{mM}$ $\mathrm{AgNO}_{3}$ (undoped state in the presence of UV). 
hybrids in doped and undoped forms exhibited the same characteristic peaks [Figs. 2(a-ii) and 2(a-iii)]. This is attributed to the fact that the polymerization of the conducting polymers on the cellulose substrate did not affect the crystalline structure of the pristine cellulose substrate and complements the fact that the conducting polymers are inherently amorphous. The doping of PPy hybrids decreased the bond distance and internal bond angle; as a consequence, resistance decreased in the polymer backbone that enhanced the conductivities of hybrid membranes. Upon undoping, the internal bond angle increased and subsequently the polymer backbone resistance increased and conductivities decreased as a result. ${ }^{(30)}$ XRD spectra of Cell-PPy hybrids containing silver nanoparticles exhibited four distinct peaks at $28,32,38.5$, and $46^{\circ}$ in the UV-irradiated doped samples [Figs. 2(b-iii) and 2(b-iv)], whereas both the undoped samples in the absence of UV showed peaks almost similar to those of cellulose II and Cell-PPy [Figs. 2(b-i) and 2(b-ii)]. ${ }^{(31)}$ A previous study suggests that the peaks around 38.50 and $44.50^{\circ}$ correspond to silver nanoparticles. Thus, the results indicate the successful formation of silver particles on Cell-PPy by UV photoreduction. Moreover, the undoped Cell-PPy hybrid in the presence of UV-irradiation was investigated to observe the effect of doping on the formation of silver particles. Such an effect was also similarly investigated in the case of the doped CellPPy hybrids [Fig. 2(b-v)], suggesting that the doping of Cell-PPy hybrids does not have any significant effect on the formation of silver particles.

The conductivities of the Cell-PPy hybrids were recorded as $0.024,0.113$, and $0.332 \mathrm{~S} / \mathrm{cm}$ at oxidant molar concentrations of $0.25,0.5$, and $1 \mathrm{M}$, whereas the conductivities were 0.078 , $0.173,0.321$, and $0.329 \mathrm{~S} / \mathrm{cm}$ at different polymerization times of 15, 30, 60, and $120 \mathrm{~min}$, respectively. The conducting behavior of Cell-PPy-Ag hybrids in the presence and absence of UV-irradiation is illustrated in Table 1. The Cell-PPy hybrids were treated with a $5 \mathrm{mM}$ solution of silver nitrate in doped and undoped forms for different time periods (20-60 min) in the presence and (1-24 h) absence of UV. The conductivity of the hybrids was clearly observed to decrease significantly in both doped and undoped forms in the presence of UV with the passage of time as compared with the initial high conductivity of $0.327 \mathrm{~S} / \mathrm{cm}$ before UV exposure to silver salt solutions. The UV exposure of Cell-PPy hybrids cleaved the conjugated structure, reducing the conductivity of Cell-PPy. Moreover, the silver nitrate concentration did not have any significant effect on the conductivity behavior of the hybrids (Table 1). There was absence of any significant effect on the conductivity behavior of Cell-PPy-Ag hybrids because the silver nanoparticles deposited using UV-assisted photoreduction were highly dispersed over the surfaces of PPy hybrid membranes highly lacking of densely packed continuous network structures to increase the conductivity of the hybrids (Figs. 3 and 4). The presence of UV

Table 1

Conductivities of Cell-PPy-Ag hybrid membranes (all membranes were prepared using $5 \mathrm{mM}$ of $\mathrm{AgNO}_{3}$ in the absence or presence of UV for different time periods).

\begin{tabular}{|c|c|c|c|c|c|c|c|c|c|c|c|}
\hline \multicolumn{6}{|c|}{ Cell-PPy-Ag (doped) } & \multicolumn{6}{|c|}{ Cell-PPy-Ag (undoped) } \\
\hline \multicolumn{3}{|c|}{ Time in the presence of UV (min) } & \multicolumn{3}{|c|}{ Time in the absence of UV (h) } & \multicolumn{3}{|c|}{ Time in the presence of UV (min) } & \multicolumn{3}{|c|}{ Time in the absence of UV (h) } \\
\hline 20 & 40 & 60 & 1 & 15 & 24 & 20 & 40 & 60 & 1 & 15 & 24 \\
\hline $5.85 \times 10^{-2}$ & $2.28 \times 10^{-2}$ & $1.18 \times 10^{-2}$ & $2.17 \times 10^{-2}$ & $2.15 \times 10^{-2}$ & $2.18 \times 10^{-2}$ & $2.9 \times 10^{-3}$ & $1.8 \times 10^{-3}$ & $1.4 \times 10^{-3}$ & $2.3 \times 10^{-3}$ & $2.2 \times 10^{-3}$ & $2.3 \times 10^{-3}$ \\
\hline $\mathrm{S} / \mathrm{cm}$ & $\mathrm{S} / \mathrm{cm}$ & $\mathrm{S} / \mathrm{cm}$ & $\mathrm{S} / \mathrm{cm}$ & $\mathrm{S} / \mathrm{cm}$ & $\mathrm{S} / \mathrm{cm}$ & $\mathrm{S} / \mathrm{cm}$ & $\mathrm{S} / \mathrm{cm}$ & $\mathrm{S} / \mathrm{cm}$ & $\mathrm{S} / \mathrm{cm}$ & $\mathrm{S} / \mathrm{cm}$ & $\mathrm{S} / \mathrm{cm}$ \\
\hline
\end{tabular}



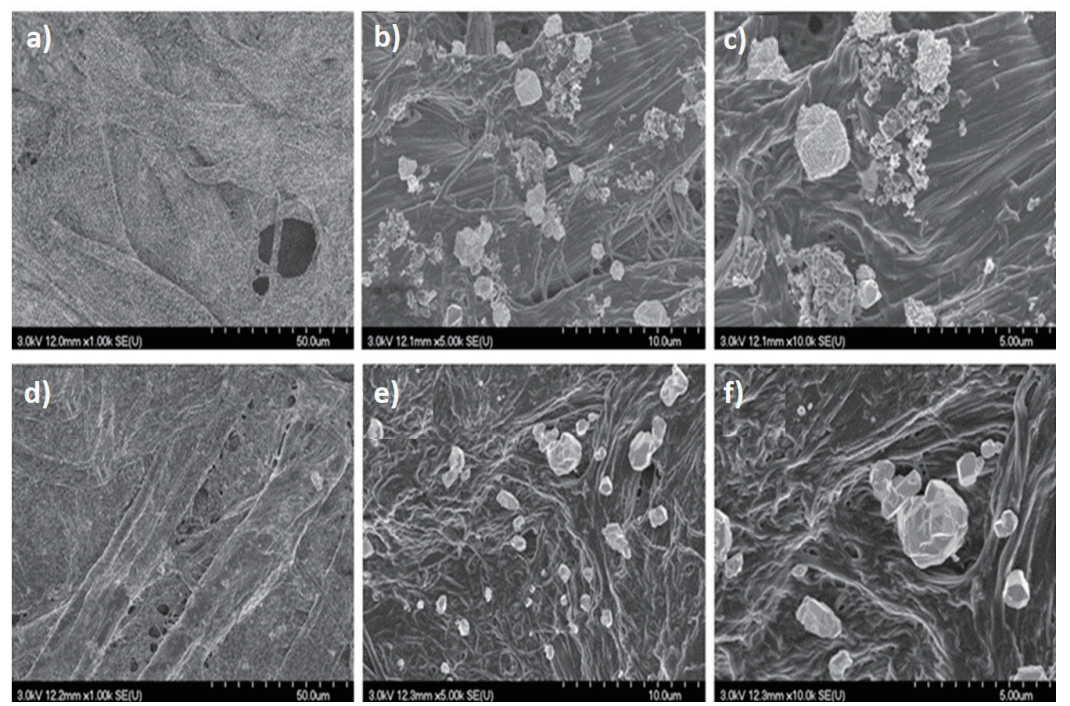

Fig. 3. SEM images of Cell-PPy hybrids decorated with silver nanoparticles: (a-c) Cell-PPy-Ag (doped) and (df) Cell-PPy-Ag (undoped) (both samples were treated with $5 \mathrm{mM} \mathrm{AgNO}$ aqueous solution in the presence of UV irradiation for $20 \mathrm{~min})$ at different magnifications $(1000 \times, 5000 \times$, and $10000 \times)$.
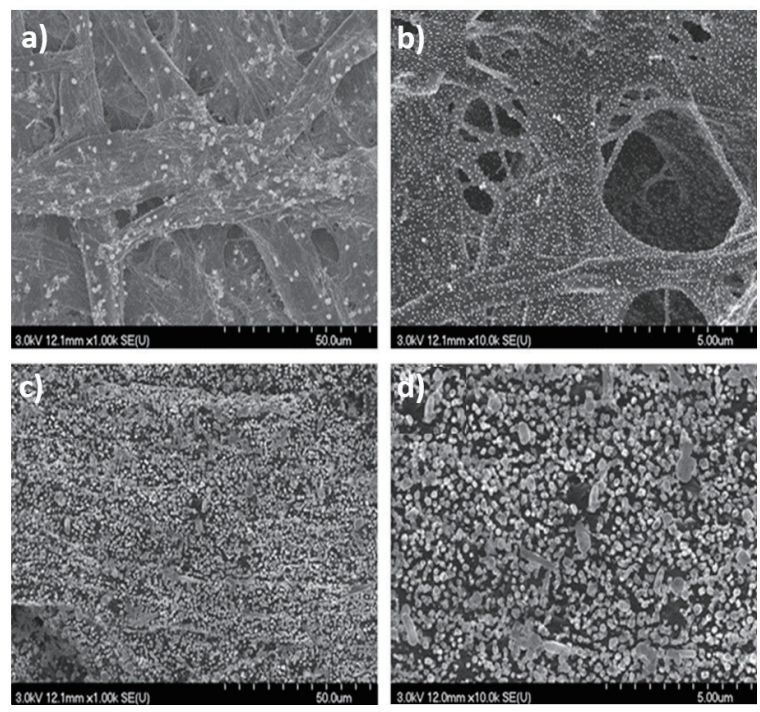

Fig. 4. SEM images of Cell-PPy-Ag hybrids with (a,b) $5 \mathrm{mM}$ and (c,d) $0.5 \mathrm{M} \mathrm{AgNO}_{3}$ (doped) aqueous solution under UV exposure for $20 \mathrm{~min}$ at different magnifications $(1000 \times$ and $10000 \times)$.

irradiation could lead to decreasing electrical conductivity resulting in a reduction in work function and an enhancement in surface band bending. ${ }^{(32)}$

The SEM images of pristine cellulose and Cell-PPy hybrids in doped and undoped forms have been compared. The morphological analysis revealed that there was no change among the pristine, doped, and undoped forms (Figs. 5 and 6). The findings show that vapor- 

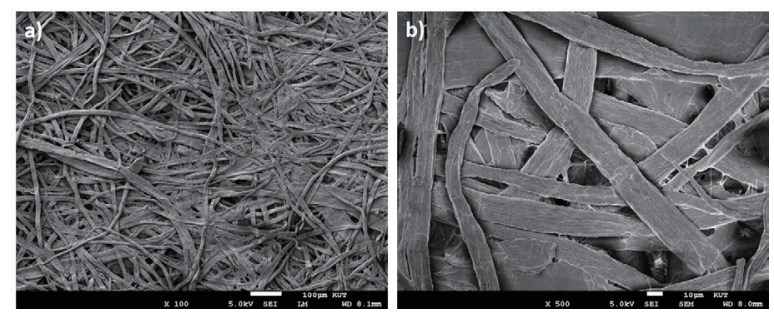

Fig. 5. SEM images of pristine cellulose membrane at different magnifications: (a) $100 \times$ and (b) 500×.
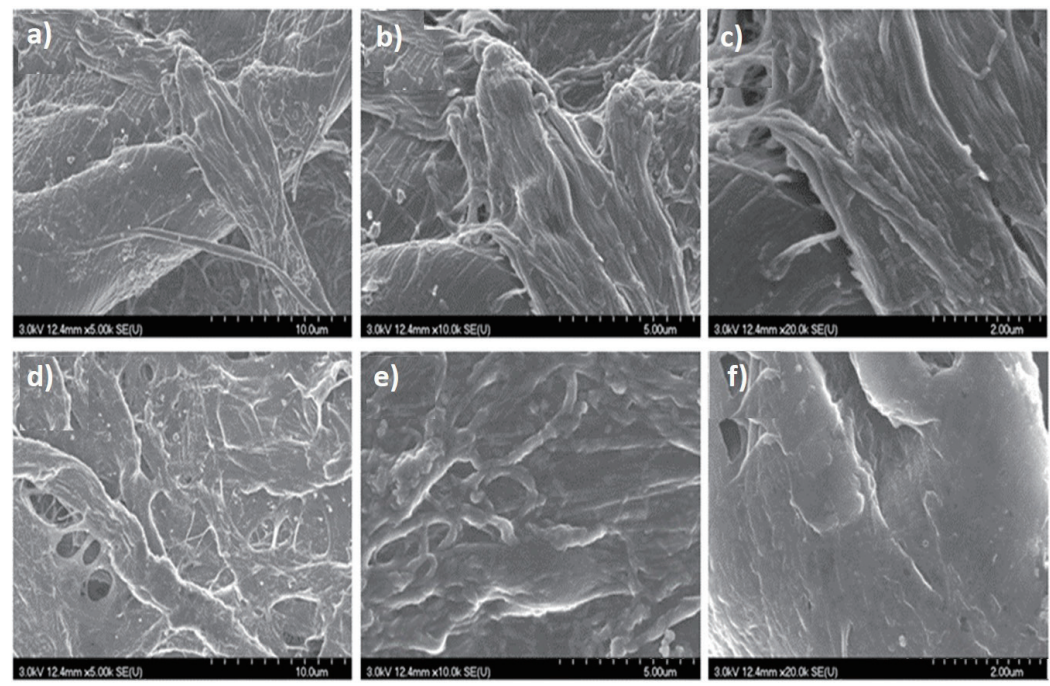

Fig. 6. SEM images of Cell-PPy hybrids: (a-c) doped (treated with $1 \% \mathrm{HCl}$ for $30 \mathrm{~min}$ ) and (d-f) undoped (treated with $1 \%$ ammonia solution for $30 \mathrm{~min})$ at different magnifications $(5000 \times, 10000 \times$, and $20000 \times)$.

phase polymerization made a uniform homogeneous coating on the cellulose surface without disrupting the surface morphology of the basal cellulose membrane. In a previous study, polypyrrole coating was accomplished on a cellulose surface owing to the formation of densely packed small spherical particles rather than a particle-free homogeneous nanocoating of polypyrrole. In this study, we report a uniform and homogenous nanocoating of PPy on the cellulose surface by green synthesis, which indicates the superiority of the presently formed Cell-PPy hybrid. ${ }^{(33)}$

Furthermore, the distribution of silver nanoparticles on the doped and undoped Cell-PPy hybrid membranes in the presence and absence of UV was confirmed by SEM (Fig. 3). The effect of silver nitrate concentration on the Cell-PPy hybrid was also studied using the SEM images. The two different silver nitrate concentrations, i.e., $0.5 \mathrm{M}$ and $5 \mathrm{mM}$, were utilized on the doped Cell-PPy followed by UV photoreduction for $20 \mathrm{~min}$. The density of $5 \mathrm{mM}$ silver nitrate was less than that of $0.5 \mathrm{M}$ silver nitrate (Fig. 4).

The amount of silver present in the Cell-PPy-Ag hybrid membranes was calculated using TGA spectra. Figure 7(a) shows the TGA results of cellulose, Cell-PPy, and Cell-PPy-Ag; two representative samples (silver nitrate concentrations of $5 \mathrm{mM}$ and $0.5 \mathrm{M}$ under $\mathrm{UV}$ irradiation on Cell-PPy in the doped form) were selected on the basis of the highest silver peak intensity of 

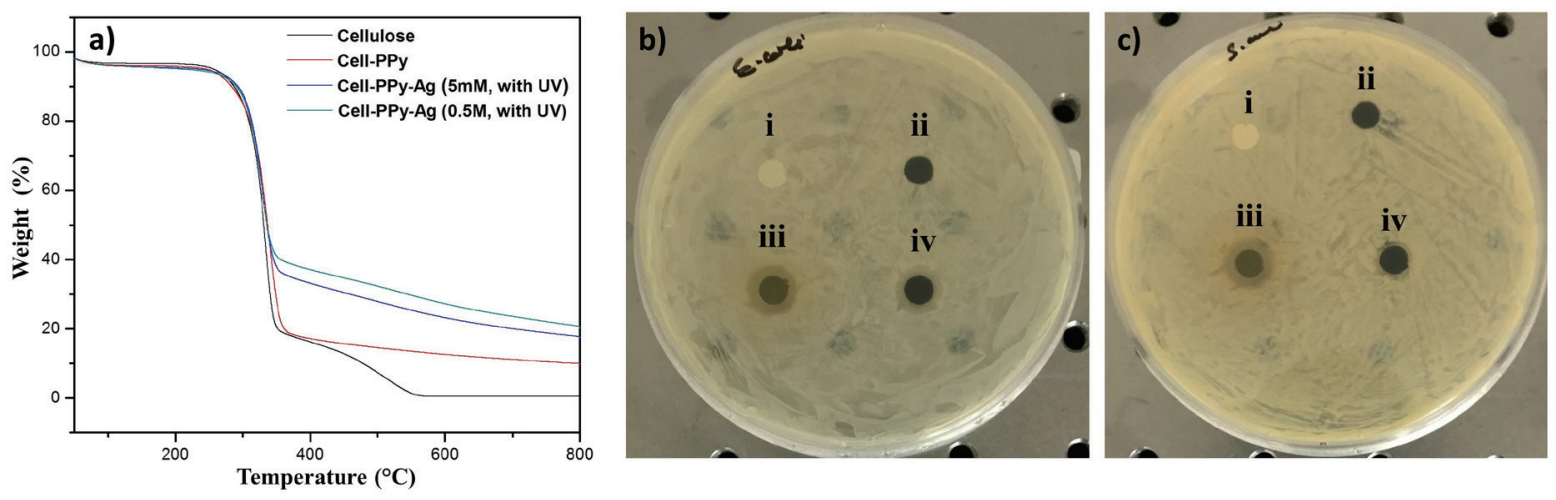

Fig. 7. (Color online) (a) TGA spectra of cellulose, Cell-PPy, Cell-PPy-Ag (0.5 M), and Cell-PPy-Ag (5 mM), and their corresponding antibacterial activity results against (b) E. coli and (c) S. aureus [(i) cellulose, (ii) Cell-PPy, (iii) Cell-PPy-Ag (0.5 M), and (iv) Cell-PPy-Ag (5 mM)].

XRD. Figure 7(a) shows that at $800{ }^{\circ} \mathrm{C}$, the residues were 17.3, 9.7, and $20.1 \%$ for Cell-PPy, CellPPy-Ag ( $5 \mathrm{mM})$, and Cell-PPy-Ag (0.5 M), respectively. As silver nanoparticles are stable up to $800{ }^{\circ} \mathrm{C}$, the percentage amount of silver nanoparticles in the hybrids was calculated to be 7.45 and $10.21 \%$ for Cell-PPy-Ag $(5 \mathrm{mM})$ and Cell-PPy-Ag $(0.5 \mathrm{M})$, respectively. ${ }^{(34,35)}$

Moreover, the thermal behavior of the hybrids revealed similar findings that the thermal stability increases with increasing concentration of silver nanoparticles on the surface, while the undecorated Cell-PPy and pristine cellulose membranes exhibited a lower thermal stability [Fig. 7(a).${ }^{(36)}$ On the basis of temperature, the TGA data obtained can be divided into three discrete regions. The first and second regions extend up to 200 and $300{ }^{\circ} \mathrm{C}$, respectively, representing a loss of water from the hybrid membranes. A minimum difference in the loss of weight is seen among the four samples. A visible distinction can be observed in the third region because of the difference in surface modification. The reduction in weight was maximum in the pristine cellulose, followed by the Cell-PPy-Ag $(5 \mathrm{mM})$ and Cell-PPy-Ag $(0.5 \mathrm{M})$ hybrid membranes. The cumulative results of SEM and TGA suggest that the formation of silver nanoparticles on the Cell-PPy membrane surface depends on the initial silver salt concentration. ${ }^{(37)}$

Both gram-negative E. coli and gram-positive $S$. aureus were utilized to study the antibacterial property of Cell-PPy-Ag hybrid membranes. The Cell-PPy membrane is considered as the control sample for the experiment. Two different concentration $(5 \mathrm{mM}$ and $0.5 \mathrm{M}$ ) of doped and 20-min-UV-photoreduced samples, on the basis of XRD, SEM, and TGA results, were chosen for the study [Figs. 7(b) and 7(c)]. ${ }^{(29)}$ Zones of inhibition with diameters of approximately 4 and $1.5 \mathrm{~mm}$ were observed in the samples deposited with $0.5 \mathrm{M}$ and 5 $\mathrm{mM}$ silver nanoparticles, indicating the antibacterial property of the developed hybrids. No zone of inhibition was formed with pristine cellulose and Cell-PPy membranes, indicating that the antibacterial property is caused by the silver decoration. ${ }^{(37)}$ The smaller zone of inhibition with $5 \mathrm{mM}$ silver nanoparticles confirms the results obtained by the SEM and TGA analyses, showing the silver-nanoparticle-concentration-dependent nature of the present hybrid membranes. The antibacterial property of AgNPs against E. coli has been well established; 


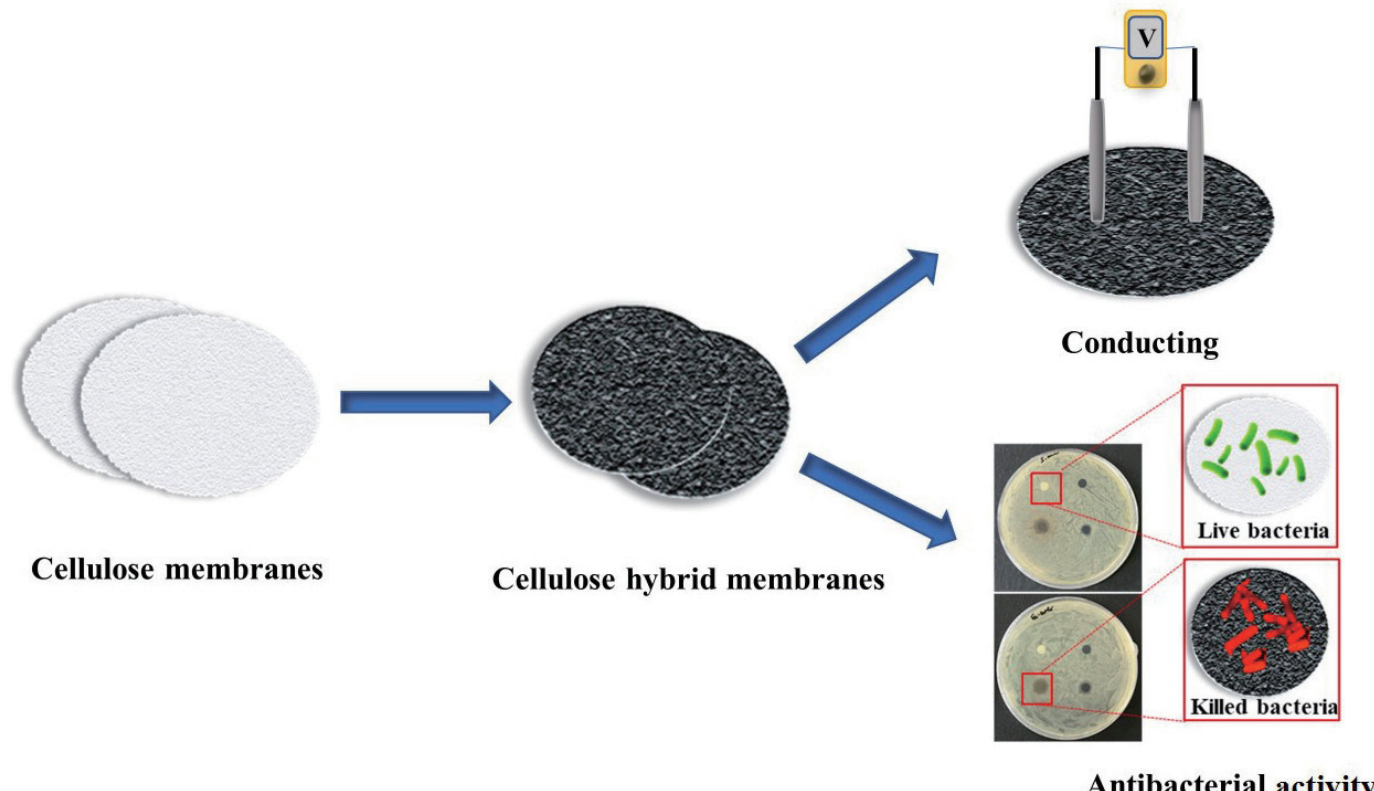

Fig. 8. (Color online) Fabrication of conducting and antibacterial dual-functional hybrid membranes.

however, reports on the antimicrobial activity of hybrid membranes with gram-positive strains such as S. aureus are highly variable. ${ }^{(38,39)}$ The current hybrid exhibits good antibacterial activity against both types of bacteria. The results indicate the applicability of our membrane to a wide range of bacteria and, thus, our membrane is useful in various fields especially in food packaging, which can easily be contaminated by both gram-positive and gram-negative bacteria. ${ }^{(40)}$

\section{Conclusions}

The vapor-phase polymerization of pyrrole monomers on the cellulose membrane and further decoration of silver nanoparticles on the surface yielded materials with distinct conducting and antibacterial dual properties (Fig. 8). The developed hybrid membranes were characterized by XRD, SEM, and TGA, revealing that dual-functional hybrid membranes can be generated by vapor-phase polymerization followed by dipping in a silver salt solution in the presence of UV irradiation. TGA results indicate that the loading amount of silver nanoparticles on the CellPPy hybrid membranes depended on the initial silver nitrate concentration. Furthermore, the antimicrobial activity was tested by the disc diffusion method, which showed the maximum antimicrobial effect with $0.5 \mathrm{M}$ silver nitrate and confirmed the initial silver nitrate-dosedependent formation of silver nanoparticles. The present research offers a simple, eco-friendly synthesis of hybrid materials, which can easily be transferred to industries for mass production. The formation of cellulose hybrid membranes with conducting polymer and silver nanoparticles can open new horizons in the field of smart paper technology and can be used in developing flexible electrochemical sensors and biomedical implants. 


\section{Acknowledgments}

This research was supported by the Basic Research Program through the National Research Foundation of Korea (NRF) funded by the Ministry of Education (2018R1A6A1A03025526 and 2017R1C1B5017763). Additionally, Sung Jea Park gratefully acknowledges the support from the Education and Research Promotion Program of KOREATECH in 2017.

\section{Conflicts of Interest}

The authors declare no conflict of interest.

\section{References}

1 T. M. Swager: Macromolecules 50 (2017) 4867. https://doi.org/10.1021/acs.macromol.7b00582

2 H. N. Muhammad Ekramul Mahmud, A. K. O. Huq, and R. b. Yahya: RSC Adv. 6 (2016) 14778. https://doi. org/10.1039/C5RA24358K

3 B. Yue, C. Wang, X. Ding, and G. G. Wallace: Electrochimi. Acta 113 (2013) 17. https://doi.org/10.1016/ j.electacta.2013.09.024.

4 F. Gao, X. Du, X. Hao, S. Li, X. An, M. Liu, N. Han, T. Wang, and G. Guan: Chem. Eng. J. 328 (2017) 293. https://doi.org/10.1016/j.cej.2017.06.177

5 X. Du, Z. Zhang, W. Liu, and Y. Deng: Nano Energy 35 (2017) 299. https://doi.org/10.1016/j.nanoen.2017.04.001

6 S. M. Unni, V. M. Dhavale, V. K. Pillai, and S. Kurungot: J. Phys. Chem. C 114 (2010) 14654. https://doi. org/10.1021/jp104664t

7 S. Geetha, C. R. K. Rao, M. Vijayan, and D. C. Trivedi: Anal. Chim. Acta 568 (2006) 119. https://doi. org/10.1016/j.aca.2005.10.011

8 M. Fuchiwaki, J. G. Martinez, and T. F. Otero: Adv. Funct. Mater. 25 (2015) 1535. https://doi.org/10.1002/ adfm.201404061

9 R. Brooke, P. Cottis, P. Talemi, M. Fabretto, P. Murphy, and D. Evans: Prog. Mater. Sci. 86 (2017) 127. https:// doi.org/10.1016/j.pmatsci.2017.01.004

10 S. Mondal and M. Sangaranarayanan: Eur. Polym. J. 71 (2015) 596. https://doi.org/10.1016/ j.eurpolymj.2015.08.027

11 R. Navik, F. Shafiq, A. Khan, M. Datta, X. Peng, M. Kamruzzaman, and Y. Cai: Fibers Polym. 18 (2017) 1115. https://doi.org/10.1007/s12221-017-6605-1

12 J. D. Larson, C. V. Fengel, N. P. Bradshaw, I. S. Romero, J. M. Leger, and A. R. Murphy: Mater. Chem. Phys. 186 (2017) 67. https://doi.org/10.1016/j.matchemphys.2016.10.030

13 J. Molina, A. Zille, J. Fernández, A. P. Souto, J. Bonastre, and F. Cases: Synth. Met. 204 (2015) 110. https://doi. org/10.1016/j.synthmet.2015.03.014

14 F. J. Schmied, C. Teichert, L. Kappel, U. Hirn, W. Bauer, and R. Schennach: Sci. Rep. 3 (2013) 2432. https:// doi.org/10.1038/srep02432

15 X. Qiu and S. Hu: Materials 6 (2013) 738. https://doi.org/10.3390/ma6030738

16 A. Yakoh, P. Rattanarat, W. Siangproh, and O. Chailapakul: Talanta 178 (2018) 134. https://doi.org/10.1016/ j.talanta.2017.09.013

17 S. M. Praveena, K. Karuppiah, and L. T. L. Than: Cellulose 25 (2018) 2647. https://doi.org/10.1007/s10570-0181747-x,

18 D. Muller, C. R. Rambo, L. M. Porto, W. H. Schreiner, and G. M. Barra: Carbohydr. Polym. 94 (2013) 655. https://doi.org/10.1016/j.carbpol.2013.01.041

19 Y. Jung, R. L. Spray, J. H. Kim, J. M. Kim, and K.-S. Choi: Chem. Commun. 46 (2010) 6566. https://doi. org/10.1039/C0CC01746A

20 S. Kim, L. K. Jang, H. S. Park, and J. Y. Lee: Sci. Rep. 6 (2016) 30475. https://doi.org/10.1038/srep30475

21 M. González and S. Saidman: Corros. Sci. 53 (2011) 276. https://doi.org/10.1016/j.corsci.2010.09.021

22 M. Li, Z. Wei, and L. Jiang: J. Mater. Chem. 18 (2008) 2276. https://doi.org/10.1039/B800289D

23 C. Wang, Y. Wang, X. Song, M. Huang, and H. Jiang: Adv. Sustainable Syst. (2018) 1800108. https:// onlinelibrary.wiley.com/doi/abs/10.1002/adsu.201800041 
24 H. Niu, H. Zhou, H. Wang, and T. Lin: Macromolecular Mater. Eng. 301 (2016) 707.

25 L. Zhai, J. Park, J. Y. Lee, D. Kim, and J. Kim: Int. J. Polym. Mater. Polym. BioMat. 67 (2018) 420. https://doi. org/10.1080/00914037.2017.1342247

26 B. H. Dong and J. P. Hinestroza: ACS Appl. Mater. Interfaces 1 (2009) 797. https://doi.org/10.1002/ mame. 201500447

27 J. M. Pringle, O. Winther-Jensen, C. Lynam, G. G. Wallace, M. Forsyth, and D. R. MacFarlane: Adv. Funct. Mater. 18 (2008) 2031. https://doi.org/10.1071/CH09006

28 Z. Hanif, S. Lee, G. H. Qasim, I. Ardiningsih, J.-A. Kim, J. Seon, S. Han, S. Hong, and M.-H. Yoon: J. Mater. Chem. A 4 (2016) 12425. https://doi.org/10.1039/C6TA01219A

29 A. W. Bauer, W. M. Kirby, J. C. Sherris, and M. Turck: Am. J. Clin. Pathol. 45 (1966) 493. http://europepmc. org/abstract/MED/5325707

30 H. Ullah, A.-u.-H. A. Shah, S. Bilal, and K. Ayub: J. Phys. Chem. C 118 (2014) 17819. https://doi.org/10.1021/ jp505626d

31 A. Adachi and J. Yamauchi: Synth. Met. 73 (1995) 101. https://doi.org/10.1073/sm/0404802101

32 Y.-J. Lin, F.-M. Yang, and C.-S. Lin: J. Appl. Phys. 102 (2007) 103702. https://doi.org/10.1063/1.2809399

33 M. Richardson, J. Johnston, and T. Borrmann: Curr. Appl. Phys. 6 (2006) 462. https://doi.org/10.1016/ j.cap.2005.11.040

34 Z. Shi, J. Tang, L. Chen, C. Yan, S. Tanvir, W. A. Anderson, R. M. Berry, and K. C. Tam: J. Mater. Chem. B 3 (2015) 603. https://doi.org/10.1039/C4TB01647E

35 N. Zhang, J. Luo, R. Liu, and X. Liu: RSC Adv. 6 (2016) 83720. https://doi.org/10.1039/C6RA19800G

36 S. Hu and Y.-L. Hsieh: Carbohydr. Polym. 131 (2015) 134. https://doi.org/10.1016/j.carbpol.2015.05.060

37 N. Alahmadi, J. Betts, T. Heinze, S. Kelly, A. Koschella, and J. Wadhawan: RSC Adv. 8 (2018) 3646. https:// doi.org/10.1039/C7RA12280B

38 M. E. Samberg, P. E. Orndorff, and N. A. Monteiro-Riviere: Nanotoxicology 5 (2011) 244. https://doi.org/10.31 $09 / 17435390.2010 .525669$

39 S. A. Masurkar, P. R. Chaudhari, V. B. Shidore, and S. P. Kamble: IET Nanobiotechnol. 6 (2012) 110. https:// doi.org/10.1049/iet-nbt.2011.0061

40 M. Mashhadi Mohammadzadeh-Vazifeh, S. M. Hosseini, S. Khajeh-Nasiri, S. Hashemi, and J. Fakhari: Iran. J. Microbiol. 7 (2015) 287. https://www.ncbi.nlm.nih.gov/pubmed/26719786 